\title{
Incidence and Prognostic Value of NPM1 and FLT3 Gene Mutations in AML with Normal Karyotype
}

\author{
Dalia Nafea ${ }^{1, *}$, Mohammed Abdel Rahman ${ }^{2}$, Dominique Boris ${ }^{3}$, Christine Perot $^{4}$, J.P. Laporte ${ }^{4}$, \\ F. Isnard ${ }^{4}$, P. Coppo ${ }^{4}$ and N.C. Gorin ${ }^{4}$ \\ ${ }^{I}$ Department of Internal Medicine-Hematology Unit, Alexandria University Egypt, ${ }^{2}$ Armed Forces Hospital Alexandria \\ Egypt, ${ }^{3}$ Henri Mondor Hospital, Paris, ${ }^{4}$ Saint Antoine Hospital, Paris
}

\begin{abstract}
NPM1 belongs to a new category of genes that function both as oncogenes and tumor suppressor genes, depending on gene dosage, expression levels, interacting partners, and compartmentalization. Nucleophosmin mutations within exon 12 have been described as the most frequent acquired molecular abnormalities in adult and pediatric acute myeloid leukaemia (AML), mutation can be observed in nearly half of patients with a normal karyotype and is associated with a favorable outcome. NPM1 mutations are characterized by the aberrant cytoplasmic localization of NPM, the absence of CD34, involvement of several cell lineages myeloid, monocytic, erythroid and megakaryocytic but not lymphoid and a high frequency of FLT3-ITD mutation. We aimed to study the prevalence, association with Flt3 mutations, and prognostic impact of NPM1 exon-12 mutations in 71 AML patients with normal karyotype. We studied NPM1 and FLT3 by RT PCR. NPM1 gene mutation was detected among 34 patients (47.9\%) and was associated with a high white blood cell count, involvement of the monocytic lineage, CD34 negativity, and high frequency of FLT3ITD. DFS and OS did not differ between mutated and unmutated NPM patients. Prospective studies are needed to confirm the definitive place of NPM mutation among patients with normal karyotype.
\end{abstract}

Keywords: AML, normal karyotype, NPM1, FLT3.

\section{INTRODUCTION}

Acute myeloid leukemia (AML) is clinically, cytogenetically and molecularly heterogeneous [1]. About $30 \%$ of cases carry recurrent chromosomal abnormalities that identify leukemia entities with clinical and prognostic features, [2] and $10 \%$ to $15 \%$ of AMLs have non random chromosomal abnormalities.

In cytogenetic analysis, $40 \%$ to $50 \%$ of AMLs show normal karyotype (AML-NK) and biologically and clinically, are the most poorly understood group $[1,3,4]$.

Mutation of the nucleophosmin gene (NPM) has recently been described as the most frequent mutation in acute myeloid leukemia [1]. NPM mutation targets $50 \%$ to $60 \%$ of adult AML-NK [5]. No case of NPM mutation has been reported among AML with recurrent cytogenetic abnormality $\mathrm{t}$ $(15 ; 17), \mathrm{t}(8 ; 21)$, inv (16), $\mathrm{t}(16 ; 16)$ and $11 \mathrm{q} 23$ abnormalities or with complex karyotype.

NPM is a protein that shuttles between the nucleus and cytoplasm, [6] is most prominent in nucleoli [7]. NPM is a molecular chaperone [8] that may prevent protein aggregation in the nucleolus and regulate the assembly and transport of peribosomal particles through the nuclear membrane [6]. It is also a target of $\mathrm{CDK}_{2}$-cyclin $\mathrm{E}$ complexes in centrosome duplication [9] and has been implicated in the regulation of

*Address correspondence to this author at the Department of Internal Medicine-Hematology Unit, Faculty of Medicine Alexandria University (Egypt), El Kartoum street el Azarita; Tel: 002034879739;

E -mail: dnafea@hotmail.com the alternate-reading-frame protein adenosine diphosphate ribosylation factor (ARF)-P53 tumor suppressor pathway [10-12].

In this study we evaluated the prevalence, association with Flt3 mutations, and prognostic impact of NPM1 exon12 mutations in 71 AML patients with normal karyotype.

\section{PATIENTS AND SAMPLES}

The study was focused on 71 AML patients (30 patients from hospital Saint Antoine Paris, and 41 from Faculty of Medicine haemotology division, Alex. University and Armed Forces hospital in Alex) with normal karyotype (age 17-68 years, median 48.9) treated according to the acute leukemia French association-90 (ALFA 90) or standard cytarabine and daunorubicin protocol over one year. A normal karyotype was defined as more than 20 normal metaphases. Samples were obtained from bone marrow or peripheral blood (with at least $70 \%$ circulating blast cells) at diagnosis.

\section{Cytogenetic Study}

Bone marrow samples were aspirated into heparinized syringes and chromosomal analyses by G-banding method was done on bone marrow cells after 1 to 3 days of unstimulated culture [13]. All cases with normal karyotype were confirmed by RT-PCR to exclude common translocations. $\mathrm{t}(8 ; 21), \mathrm{t}(9 ; 11), \mathrm{t}(15 ; 17), \mathrm{t}(16 ; 16)$ and inv (16).

\section{Screening for Mutations of the FLT3}

Total RNA was isolated from thawed samples using RNeasy columns (Qiagen, Valencia, CA) and reverse tran- 
scribed. Reverse transcription (RT) was performed followed by polymerase chain reaction (PCR) with primers $\mathrm{R} 5$ (5)TGT CGA GCA GTA CTC TAA ACA-3') and R6 (5`-ATC CTA GTA CCT TCC C AAACTC-3') [14]. Using the onestep RT-PCR kit (Invitrogen, Rockville, MD). Products were subjected to electrophoresis on $2.5 \%$ agarose gels to identify bands migrating above the expected $365 \mathrm{bp}$ size of the wildtype FLT3 fragment. Dideoxy sequencing was performed on selected samples to confirm FLT3/ITD status. For identification of D835 point mutations. RT-PCR was performed on RNA samples using primers from exon 17 (5-TTCACAGAGACCTG GCCG-3`), and (5'-TTG CCC CTGACAACATAG-3`). This was followed with EcoRV digestion and electrophoresis on $1.8 \%$ agarose gels [15].

\section{Screening for Mutations of the NPM1 Gene}

Analysis of NPM exon 12 mutation was done as described by Falini et al. [5].

All samples taken at diagnosis were confirmed to contain more than $80 \%$ leukemia cells after enrichment by centrifugation and confirmed by microscopic review of Wrightstained, the isolated cells were frozen and stored at $-80^{\circ} \mathrm{C}$. RNA was extracted with the Qiagen total RNA extraction mini kit (Qiagen, Valencia, CA).

The isolated RNA was reverse transcribed into cDNA, $\left(25^{\circ} \mathrm{C}\right.$ for 10 minutes, followed $37^{\circ} \mathrm{C}$ for 69 minute, and $95^{\circ} \mathrm{C}$ for 5 minute). The final volume for PCR reaction was $35 \mu \mathrm{L}$ containing $200 \mathrm{ng} \mathrm{cDNA}, 200 \mathrm{nmol} / \mathrm{L}$ deoxynucleotide triphosphate, $2 \mathrm{mmol} / \mathrm{L} \mathrm{MgSO}, 140 \mathrm{nmol} / \mathrm{L}$ of each primer, using the primers NPM1-F, (5 -TTAACTCTCTGGTGGTAGAATGAA-3'), NPM1-R, (5`-CAAGACTATT TGCCATTCCTAAC-3'), and 2ul DNA Specific Master Hybridization Probes labeled with FAM and TAMRA dyes [5], and 1 unit of AmpliTaq Gold polymerase (Applied Biosystems, Foster City, CA). Total RNA concentration was quantified with using house keeping gene (GPDH) labeled with different dyes. Real-time polymerase chain reaction (PCR) assays using ABI PRISM 7000 sequence Detection System (Applied Biosystems) was done by heating at $50^{\circ} \mathrm{C}$ for 2 minutes, $95^{\circ} \mathrm{C}$ for 10 minutes, followed by 35 cycles of $95^{\circ} \mathrm{C}$ for 40 seconds, $49^{\circ} \mathrm{C}$ for 1 minute, and $72^{\circ} \mathrm{C}$ for 1 minute, with a final step for 10 minutes at $72^{\circ} \mathrm{C}$.

Real-time polymerase chain reaction (PCR) assays using ABI PRISM ${ }^{\circledR} 7000$ sequence Detection System (Applied Biosystems) data wereanalyzed using Real-time polymerase chain reaction $(\mathrm{PCR})$ assays using $\mathrm{ABI}$ PRISM $^{\circledR} 7000$ sequence Detection.

Amplification curves of RNA extracted from BM of AML patients by Real time PCR. The X-axis represents the PCR cycle number at which the cDNA started the amplification: the Y-axis represents the normalized reporter signal minus the base line signal.

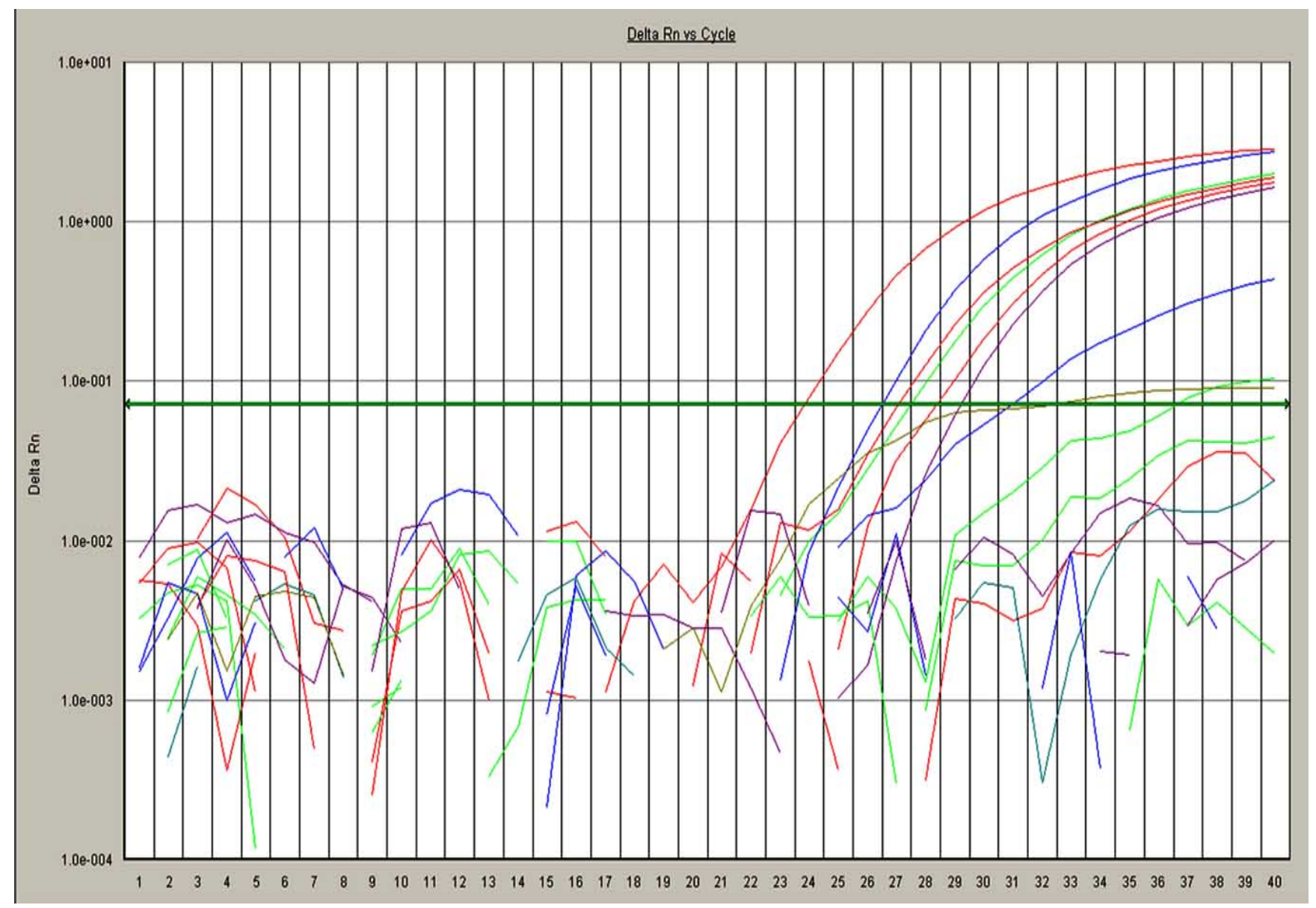




\section{Statistical Analysis}

Survival curves were calculated for overall survival (OS), disease-free survival (DFS) according to Kaplan-Meier and compared using the 2 sided log-rank test. OS and DFS were calculated from time of diagnosis to the end of follow-up. Fisher exact test compared NPM1 mutation status and student $T$ test compared NPM1 mutation status and continuous variables. For all analysis, results were significant at a $p$ level less than .05 at both sides. SPSS version 15.00 software (Chicago,IL) was used for statistical analysis.

\section{RESULTS}

The study was focused on 71 patients with normal karyotype (Age range 17-68 years median 48.9). 45 patients achieved complete remission, among whom 42 underwent transplantation (26 allogeneic and 16 autologous). NPM1 gene mutation was detected among 34 patients (47.9\%). Patients characteristics at presentation are mentioned in Table 1.

\section{NPM1 Morphology and Immunophenotypes}

Frequency of NPM1 gene mutation among FAB subgroups was heterogenous, ranged from $11.5 \%$ among FABM1 to $52.9 \%$ among FABM5. The mutation was significantly higher among FABM5 compared with the total group. $(\mathrm{P}<0.001)$. We didn't find the mutation among FAB M0. NPM1 mutated group had significantly lower expression of $\mathrm{CD}_{34}(\mathrm{P}<0.001)$ in comparison with unmutated NPM1 group.

\section{NPM and Biologic Parameters}

In the NPM1 mutated group, the white blood cell count was significantly higher (mean $40.58 \mathrm{P}<0.031$ ) than the unmutated group, there was no significant difference in age and sex ratio between $\mathrm{NPM}^{+}$and $\mathrm{NPM}^{-}$groups. $(\mathrm{P}>0.005)$.

\section{NPM and Flt3 Gene Mutations}

- Among 34 patients who were positive for NPM1, $17(50 \%)$ were positive for dual NPM1 and Flt3ITD mutations.

- Flt3 mutation has been detected in $36.6 \%$ of our AML NK patients. Patients with FLT3ITD mutations who received BMT had significantly improved DFS in comparison with FLT3ITD positive who were treated with multiple consolidation courses. $(\mathrm{P}<0.024)$.

\section{Prognosis of NPM Mutations in Adult AML with Normal Karyotype}

Of the 71 patients, $45(63.4 \%)$ achieved complete remission after induction chemotherapy, there was difference in CR rates between mutated NPM1 and unmutated NPM1 patients not reaching significant level. (67.6\% versus $59.5 \%)$. CR rate was not influenced by Flt3 mutations.

The global 2 years OS of this study was $56 \%$, there was no significant difference regarding outcome between mutated and unmutated NPM1 groups (82.4\% versus $78.4 \%$ ). No difference in DFS between mutated NPM1 and unmutated NPM1 AML NK patients (58.5\% versus $59.5 \%)$.

The presence of Flt3 was not a prognostic factor for DFS $\left(\mathrm{NPM}^{+}\right.$Flt3 $^{+}$DFS: $58.8 \%$, versus $58.8 \%$ in $\mathrm{NPM}^{+} \mathrm{Flt3}^{-}$) (Fig. 1).
A difference in outcome (OS) was observed between $\mathrm{NPM}^{+} \mathrm{Flt}^{-}$and $\mathrm{NPM}^{+} \mathrm{Flt}^{+} 82.4 \%$ versus $76.5 \%$ without reaching a statistical significance (Fig. 2).

\section{DISCUSSION}

Our study was focused on 71 AML patients with normal karyotype among them $34(47.9 \%)$ patients were positive for NPM mutation, this incidence is nearly similar to that reported by Falini et al. who discovered that NPM1 gene mutation target 50 to $60 \%$ of adult AML NK [5].

NPM mutations closely associate with de novo AML, as AML secondary to myeloproliferative disorders, myelodysplasia and therapy-related rarely show cytoplasmic NPM mutations [5].

In our study the frequency of NPM mutation among FAB subgroups was heterogenous being markedly higher among FAB M5, this finding coincide with several reports which found that NPM mutation was frequent among FAB groups with monocytic differentiation [16].

There was no sex or age prevalence for NPM mutation where other clinical studies found that NPM mutations are significantly more frequent in females. Cases of $\mathrm{NPM}^{+}$are associated with higher white blood cell counts and lower expression of $\mathrm{CD}^{34}$ [17].

FLT3ITD mutation was seen near twice as often in cases of $\mathrm{NPM}^{+}$AML as it was in cases of $\mathrm{NPM}^{-} \mathrm{AML}$, the close association between Flt3ITD and NPM mutations in clinical practice suggests that these genetic lesions may co-operate to promote leukemic transformation [16-19].

Similar to previous Italian study, there was difference in $\mathrm{CR}$ rates between $\mathrm{NPM}^{+}$and $\mathrm{NPM}^{-}$patients $(76.6 \%$ versus $59.5 \%)$. The association of NPM1 mutation with better response to induction therapy can be explained by the ability of mutated NPM proteins to maintain the dimerization domain and are therefore able to form heterodimers with the wild type NPM1, this may lead to subcellular dislocation of the wild type protein by the mutated NPM1. This altered distribution plays a key role in the regulation of ARF-P53 Pathway and centrosome duplication [20-23].

As it was shown that daunorubicin induce nucleoplasmic dislocation of NPM1, which was associated with increased apoptosis, [24] the subcellular relocation of wild type NPM1 in NPM mutated AML may lead to increase sensitivity to chemotherapeutic agents.

Monitoring of minimal residual disease in AML NK is hampered by the lack of reliable molecular markers. Flt3 and NPM mutations can be used for this purpose, as FLT3 and NPM1 mutations have been detected among $36.6 \%$ and 47.9\% AML NK patients respectively.

In contrary to Falini study, [25] there was no difference in DFS between $\mathrm{NPM}^{+}$and $\mathrm{NPM}^{-}$patients and no significant association between $\mathrm{NPM}^{+}$and patient outcome (OS). This can be explained by the high association of this mutation with numerous bad prognostic factors such as high WBC count, FAB M5 and the presence of Flt3 mutations.

Most importantly, this study demonstrated that DFS in $\mathrm{NPM}^{+}$patients was not influenced by concomitant Flt3 
Table 1. Patients Characteristics

\begin{tabular}{|c|c|c|c|c|c|c|c|}
\hline Patient $N=$ & Age & Sex & FAB & $\mathrm{WBcx} 10^{9} / \mathrm{L}$ & NPM1 & FIt3/ITD & Transpantation \\
\hline 1 & 67 & M & M0 & 11,42 & - & - & 1 \\
\hline 3 & 66 & M & M4 & 44 & - & - & 0 \\
\hline 5 & 50 & M & M1 & 34 & - & + & 0 \\
\hline 6 & 37 & M & M1 & 42 & + & + & 2 \\
\hline 7 & 38 & $\mathrm{~F}$ & M1 & 37,38 & - & - & 2 \\
\hline 8 & 26 & M & M4 & 2,5 & - & - & 2 \\
\hline 11 & 54 & M & M2 & 144 & - & - & 2 \\
\hline 12 & 66 & M & M1 & 126 & + & + & 1 \\
\hline 13 & 44 & M & M2 & 17,7 & - & - & 2 \\
\hline 14 & 59 & $\mathrm{~F}$ & M5 & 64 & + & + & 1 \\
\hline 15 & 44 & M & M0 & 1,2 & - & - & 2 \\
\hline 16 & 42 & M & M5 & 49 & + & - & 0 \\
\hline 17 & 58 & M & M4 & 28 & - & + & 0 \\
\hline 23 & 45 & $\mathrm{~F}$ & M2 & 2,21 & - & + & 0 \\
\hline 24 & 25 & $\mathrm{M}$ & M1 & 2,5 & + & - & 2 \\
\hline 25 & 36 & $\mathrm{M}$ & M5 & 62 & + & - & 1 \\
\hline 26 & 36 & $\mathrm{M}$ & M1 & 18 & - & - & 2 \\
\hline 27 & 44 & $\mathrm{M}$ & M5 & 23 & - & - & 0 \\
\hline 28 & 51 & F & M4 & 43,1 & + & - & 2 \\
\hline 29 & 39 & $\mathrm{M}$ & M4 & 9,5 & - & - & 0 \\
\hline 30 & 31 & $\mathrm{M}$ & M4 & 209 & + & + & 2 \\
\hline 31 & 37 & $\mathrm{M}$ & M4 & 71 & + & + & 2 \\
\hline 32 & 42 & $\mathrm{M}$ & M0 & 13,8 & - & - & 1 \\
\hline 33 & 46 & $\mathrm{M}$ & M4 & 32 & + & - & 2 \\
\hline 34 & 35 & $\mathrm{M}$ & M4 & 1,9 & - & - & 0 \\
\hline 35 & 25 & F & M5 & 12,7 & - & - & 2 \\
\hline 36 & 43 & $\mathrm{M}$ & M1 & 27,9 & - & + & 0 \\
\hline
\end{tabular}


Table 1. contd....

\begin{tabular}{|c|c|c|c|c|c|c|c|}
\hline Patient $\mathrm{N}=$ & Age & Sex & FAB & $\mathrm{WBcx} 10^{9} / \mathrm{L}$ & NPM1 & Flt3/ITD & Transpantation \\
\hline 37 & 38 & $\mathrm{M}$ & M2 & 14,2 & + & + & 2 \\
\hline 38 & 35 & $\mathrm{M}$ & M1 & 17 & - & - & 2 \\
\hline 39 & 29 & $\mathrm{M}$ & M4 & 2,4 & - & - & 0 \\
\hline 40 & 50 & $\mathrm{M}$ & M6 & 11,5 & + & - & 0 \\
\hline 41 & 49 & $\mathrm{M}$ & M1 & 16 & - & - & 1 \\
\hline 42 & 35 & & M5 & 56 & + & - & 2 \\
\hline 43 & 60 & $\mathrm{M}$ & M1 & 12,7 & + & + & 1 \\
\hline 44 & 42 & $\mathrm{M}$ & M2 & 13 & - & - & 0 \\
\hline 45 & 39 & $\mathrm{~F}$ & M1 & 22 & - & - & 0 \\
\hline 46 & 51 & $\mathrm{M}$ & M5 & 44 & + & + & 2 \\
\hline 47 & 40 & M & M5 & 35 & + & - & 1 \\
\hline 48 & 39 & $\mathrm{~F}$ & M4 & 22 & - & + & 0 \\
\hline 49 & 63 & M & M1 & 40 & + & + & 1 \\
\hline 50 & 27 & $\mathrm{~F}$ & M2 & 1,8 & - & - & 0 \\
\hline 51 & 55 & $\mathrm{~F}$ & M2 & 24,2 & + & + & 1 \\
\hline 52 & 22 & $\mathrm{M}$ & M2 & 72,8 & + & - & 0 \\
\hline 53 & 52 & $\mathrm{M}$ & M5 & 7,1 & - & - & 2 \\
\hline 54 & 43 & $\mathrm{~F}$ & M6 & 4,3 & - & + & 0 \\
\hline 55 & 40 & $\mathrm{~F}$ & M1 & 3,3 & + & - & 0 \\
\hline 56 & 32 & $\mathrm{~F}$ & M5 & 53 & + & - & 1 \\
\hline 57 & 35 & M & M0 & 12,6 & - & - & 2 \\
\hline 58 & 40 & M & M5 & 49 & - & + & 2 \\
\hline 59 & 39 & $\mathrm{~F}$ & M4 & 53 & + & - & 0 \\
\hline 60 & 39 & $\mathrm{M}$ & M4 & 3,4 & - & - & 0 \\
\hline 61 & 42 & $\mathrm{~F}$ & M2 & 13,3 & - & - & 0 \\
\hline 62 & 50 & $\mathrm{M}$ & M4 & 17,8 & + & + & 2 \\
\hline 63 & 57 & M & M5 & 32,5 & + & + & 1 \\
\hline 64 & 36 & M & M4 & 47 & + & + & 2 \\
\hline 65 & 42 & M & M0 & 11 & - & - & 2 \\
\hline 66 & 39 & $\mathrm{~F}$ & M5 & 22 & + & - & 1 \\
\hline 67 & 45 & M & M4 & 63 & - & + & 0 \\
\hline 68 & 50 & $\mathrm{~F}$ & M2 & 3,6 & - & - & 0 \\
\hline 69 & 38 & $\mathrm{M}$ & M4 & 25 & - & - & 0 \\
\hline 70 & 50 & $\mathrm{~F}$ & M1 & 16,4 & + & + & 1 \\
\hline 71 & 17 & $\mathrm{~F}$ & M4 & 39 & + & + & 0 \\
\hline
\end{tabular}


mutation which is a recognized predicator of bad prognosis [26].

The improved DFS for FLT3/ITD patients who received BMT as consolidation is again consistent with the observation of others [27]. Thus the intensity of treatment could affect the clinical outcome of patients with AML expressing FLT3/ITD mutation.

Finally, NPM mutation is associated with responsiveness to induction therapy, although its role (alone or in combination with Flt3) in predicting the outcome of AML NK after remissions remains to be defined. Prospective studies are needed to confirm the definitive place of NPM mutation among patients with normal karyotype.

$\begin{array}{ll}-\mathrm{NPM}+\mathrm{ve} \& \mathrm{FLT3}+\mathrm{ve} & -\mathrm{NPM}+\mathrm{ve} \& \mathrm{FLT3}-\mathrm{ve} \\ -\mathrm{NPM}+\mathrm{ve} & -\mathrm{NPM}-\mathrm{ve}\end{array}$

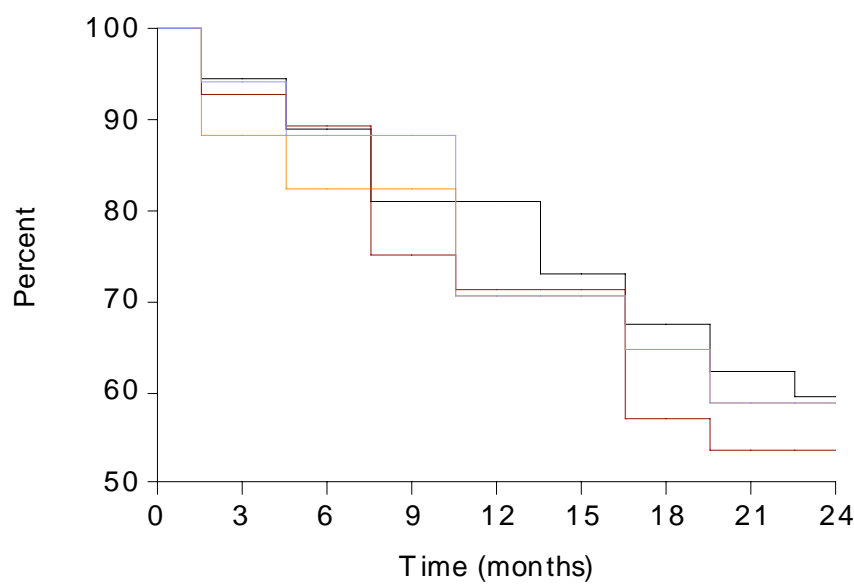

Fig. (1). Kaplan-Meier analysis of AML with normal karyotype bearing mutated or unmutated NPM1 and FLT3 status for DFS. Results were significant at a level of $\mathrm{P}<0.05$.

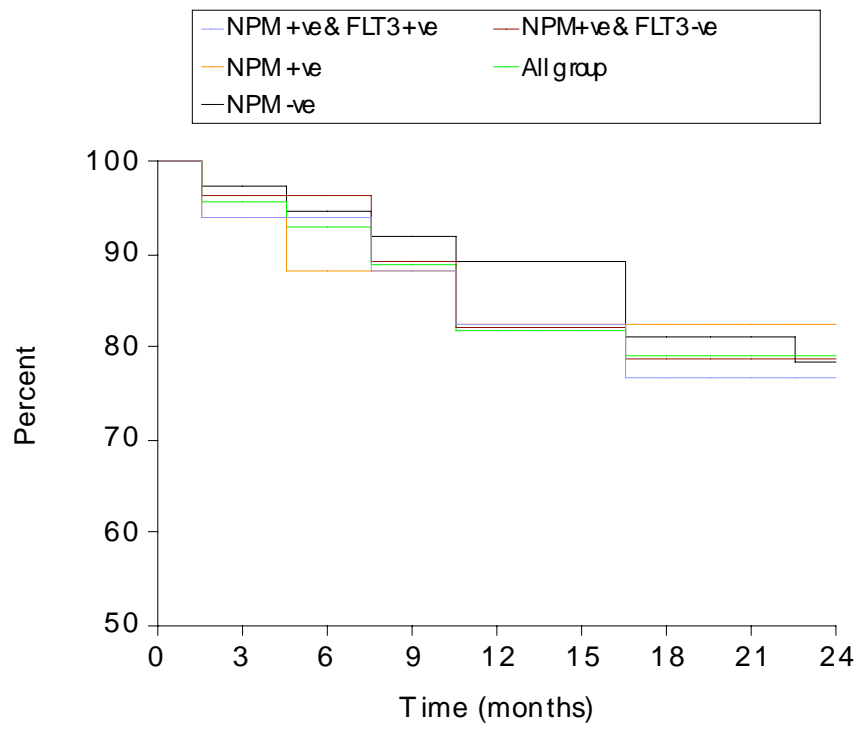

Fig. (2). Kaplan-Meier analysis of AML with normal karyotype bearing mutated or unmutated NPM1 and FLT3 status for OS. Results were significant at a level of $\mathrm{P}<0.05$.

\section{REFERENCES}

[1] Gilliland DG, Jordan CT, Felix CA. The molecular basis of leukemia. Hematology Am Soc Hematol Educ Program 2004; 80-97.

[2] Jaffe E, Harris N, Stein H, Vardiman J. Pathology and genetics of tumours of hematopoietic and lymphoid tissues. Lyon France: IARC Press 2001.

[3] Grimwade D, Walker H, Oliver F, et al. The importance of diagnostic cytogenetics on outcome in AML: analysis of 1612 patients entered into the MRC AML to trial. The Medical Research Council Adult and children's leukemia working parties. Blood 1998; 92: 2322-33.

[4] Marcucci G, Mrozek K, Bloomfield CD. Molecular heterogeneity and prognostic biomarkers in adults with acute myeloid leukemia and normal cytogenetics. Curr Opin Hemetol 2005; 12: 68-75.

[5] Falini B, Mecucci C, Tiacci E, et al. Cytoplasmic nucleophosmin in acute myelogenous leukemia with a normal karyotype. $\mathrm{N}$ Engl J Med 2005; 352: 254-66.

[6] Borer RA, Lehner CF, Eppenberger HM, Nigg EA. Major nucleolar proteins shuttle between nucleus and cytoplam. Cell 1989; 56: 379-90.

[7] Cordell JL, Pulford KA, Bigerna B, et al. Detection of normal and chimeric nucleophosmin in human cells. Blood 1999; 93: 63242 .

[8] Dumbar TS, Gentry GA, Olson MO. Interaction of nucleolar phosphoprotein B23 with nucleic acids. Biochemistry 1989; 28: $9495-$ 501.

[9] Okuda M, Horn HF, Tarapore P. et al. Nucleophosmin B23 is a target of CDK2/cyclin E in centrosome duplication. Cell 2000; 103: 127-40.

[10] Bertwistle D, Sugimoto M, Sherr CJ. Physical and functional interactions of the Arf tumor suppressor protein with nucleophosmin $/ \mathrm{B}_{23}$. Mol Cell Biol 2004; 24: 985-96.

[11] Colombo E, Marine JC, Danovi D, Falini B, Pelicci PG. Nucleophosmin regulates the stability and transcriptional activity of $\mathrm{P}_{53}$. Nat Cell Biol 2002; 4: 529-33.

[12] Kurki S, Peltonen K, Latonen L, et al. Nucleolar protein NPM interacts with HDM2 and protects tumor suppressor protein 53 from HDM2-medicated degradation. Cancer cell 2004; 5: 465-75.

[13] Tien HF, Wang CH, Lin CH, Linn MT. Correlation of cytogenetic results with immunophenotype, genotype,clinical features, and RAS mutation in acute myeloid leukemia. A study on 235 chinese patients in Taiwan. Cancer Genet 1995; 85: 60-8.

[14] Nakao M, Yokota S. Internal tandem duplication of the FLT3 gene found in acute myeloid leukemia. Leukemia 1996; 10: 1911-8.

[15] Yamamoyo Y, Kiyoi H. Activating mutation of D835 within activation loop of FLT3 in human hematologic malignancies. Blood 2001; 97: 2434-9.

[16] Schnittger S, Schoch C, Kern Q. Nucleophosmin gene mutations are predictors of favorable prognosis in acute myelogenous leukemia with a normal karyotype. Blood 2005; 106: 3733-9.

[17] Dohner K, Schlenk RF, Habdank M, et al. Mutant nucleophosmin (NPM1) predicts favorable prognosis in younger adults with acute myeloid leukemia and normal cytogenetics: interaction with other gene mutations. Blood 2005; 106: 3740-6.

[18] Verhaak RG, Goudswaard CS, Van putten W, et al. Mutations in nucleophosmin (NPM1) in acute myeloid leukemia (AML): association with other gene abnormalities and previously established gene expression signatures and their favorable prognostic significance. Blood 2005; 106: 3747-54.

[19] Thied C, Koch S, Creutzig E, et al. Prevalence and prognostic impact of NPM1 mutations in 1485 adult patients with acute myeloid leukemia (AML). Blood 2006; 107: 4011-20.

[20] Colombo E, Marine JC, Danovi D, Falini B, Pelicci PG. Nucleophosmin regulates the stability and transcriptional activity of P53. Nat Cell Biol 2002; 4: 529-33.

[21] Bertwistle D, Sugimoto M, Sherr CJ. Physical and functional interactions of the Arf tumor suppressor protein with nucleophosmin/B23. Mol Cell Biol 2004; 24: 985-96.

[22] Brady G, Funk A, Mattern J, Schutz G, Brown R. Use of gene transfer and a novel cosmid rescue strategy to isolate transforming sequences. EMBO J 1985; 4: 2583-8.

[23] Okuda M, Horn HF, Tarapore P, et al. Nucleophosmin/B23 is a target of CDK2/cyclin E in centrosome duplication. Cell 2000; 103: $127-40$. 
[24] Chan PK, Chan FY. A study of correlation between NPM-Translocation and apoptosis in cells induced by daunomycin. Biochem Pharmacol 1999; 57: 1265-73.

[25] Schnittger S, Schoch C, Kern W, Falini B. Nucleophosmin gene mutations are predictors of favorable prognosis in acute myelogenous leukemia with a normal karyotype. Blood 2005; 106: 3733-9.
[26] Wu Dp, Yan LZ, Yan 1, Chen SN, Liang JY. A study of NPM1 and FLT3 gene mutations in acute myeloid leukemia. Zhonghu Nei Ke Z Zhi 2007; 46: 907-10.

[27] Levis M, Smith BD, Garrett E, et al. The clinical outcome of patients with acute myeloid leukemia expressing FIT3 Internal tandem Duplication mutations could be altered by treatment regimen. J Appl Res 2003; 3: 296-302.

(C) Nafea et al.; Licensee Bentham Open.

This is an open access article licensed under the terms of the Creative Commons Attribution Non-Commercial License (http://creativecommons.org/licenses/ by-nc/3.0/) which permits unrestricted, non-commercial use, distribution and reproduction in any medium, provided the work is properly cited. 